\title{
Detection of Noncarboxymethyllysine and Carboxymethyllysine Advanced Glycation End Products (AGE) in Serum of Diabetic Patients
}

\author{
Masayoshi Takeuchi, ${ }^{1}$ Zenji Makita, $^{2}$ Katsuyuki Yanagisawa, ${ }^{2}$ \\ Yukihiko Kameda, ${ }^{1}$ and Takao Koike ${ }^{2}$ \\ ${ }^{1}$ Department of Biochemistry, Faculty of Pharmaceutical Science, \\ Hokuriku University, Kanazawa, Japan \\ ${ }^{2}$ Department of Internal Medicine $\Pi$, Hokkaido University School of \\ Medicine, Sapporo, Japan \\ Communicated by R. Bucala. Accepted April 10, 1999.
}

\begin{abstract}
Background: The advanced stage of the Maillard reaction, which leads to the formation of advanced glycation end products (AGE), plays an important role in the pathogenesis of angiopathy in diabetic patients and in the aging process. $\mathbf{N}^{\epsilon}$-(carboxymethyl)lysine (CML) is thought to be an important epitope for many of currently available AGE antibodies. However, recent findings have indicated that a major source of $\mathrm{CML}$ may be by pathways other than glycation. A distinction between CML and non-CML AGE may increase our understanding of AGE formation in vivo. In the present study, we prepared antibodies directed against CML and non-CML AGE.

Materials and Methods: AGE-rabbit serum albumin prepared by 4,8 , and 12 weeks of incubation with glucose was used to immunize rabbits, and a high-titer AGE-specific antiserum was obtained without affinity for the carrier protein. To separate CML and non-CML AGE antibodies, the anti-AGE antiserum was subjected to affinity chromatography on a column coupled with AGEBSA and CML-BSA. Two different antibodies were obtained, one reacting specifically with $\mathrm{CML}$ and the other reacting with non-CML AGE. Circulating levels of CML and non-CML AGE were measured in 66 type 2 diabetic
\end{abstract}

patients without uremia by means of the competitive ELISA. Size distribution and clearance by hemodialysis detected by non-CML AGE and CML were assessed in serum from diabetic patients on hemodialysis.

Results: The serum non-CML AGE level in type 2 diabetic patients was significantly correlated with the mean fasting blood glucose level over the previous 2 months ( $r=0.498, p<0.0001)$ or the previous 1 month $(r=$ 0.446, $p=0.0002)$ and with $\mathrm{HbA}_{1 \mathrm{c}}(r=0.375, p=$ 0.0019), but the CML AGE level was not correlated with these clinical parameters. The CML and non-CML AGE were detected as four peaks with apparent molecular weights of $200,65,1.15$, and $0.85 \mathrm{kD}$. The hemodialysis treatment did not affect the high-molecular-weight protein fractions. Although the low-molecular-weight peptide fractions (absorbance at $280 \mathrm{~nm}$ and fluorescence) were decreased by hemodialysis, there was no difference before and after dialysis in the non-CML AGE- and CML-peptide fractions (1.15 and $0.85 \mathrm{kD}$ fractions).

Conclusions: We propose that both $\mathrm{CML}$ and non-CML AGE are present in the blood and that non-CML AGE rather than $C M L A G E$ should be more closely evaluated when investigating the pathophysiology of AGE-related diseases.

\section{Introduction}

Glucose reacts nonenzymatically with protein amino groups to initiate a post-translational modification process known as nonenzymatic glycosyl-

Address correspondence and reprint requests to: Dr. Zenji Makita, Department of Internal Medicine II, Hokkaido University School of Medicine, N-15, W-7, Kita-ku, 060-8638 Sapporo, Japan. Phone: 81-11-716-1161 (ext. 5915); Fax: 81-11-736-0958; E-mail:zmakita@med.hokudai.ac.jp ation, or glycation. This process begins with the conversion of reversible Schiff base adducts to more stable, covalently bound Amadori rearrangement products (1). Over the course of weeks to months, the Amadori products undergo further rearrangement reactions to form irreversibly bound moieties called advanced glycation end products (AGE) (1). Many AGEs have fluorescence and covalent cross-linking properties. 
Recent studies have suggested a potential role of AGE in atherosclerosis, aging, and diabetic complications (1). The structures of several types of AGE have been described, including pyrraline (2), pentosidine (3), $\mathrm{N}^{\epsilon}$-(carboxymethyl) lysine (CML) (4), crosslines (5), and imidazolones (6). Immunological studies using antibodies specific for these compounds have confirmed their presence in vivo $(2,3,5-7)$. However, whether one compound has a major role in the pathogenesis of the these diseases or whether several compounds are involved remains to be determined. Recent studies have demonstrated that a CML-protein adduct is a major epitope for monoclonal and polyclonal anti-AGE antibodies $(8,9)$, and other workers have reported that CML is increased in serum protein obtained from diabetic patients (7). However, Fu et al. (10) clearly demonstrated that the major source of CML was by lipid peroxidation, not glycation. In addition, Wells-Knecht et al. (11) reported evidence against a generalized increase of CML in the skin of diabetes. These findings suggest that CML may be a marker of oxidation rather than a major source of AGE, and that non-CML AGE might play a more important role in the complications of diabetes. The nonphysiological protein-to-protein cross-linking nature of AGE is believed to play an important role in diabetic complications and other AGE-related disorders. An AGE crosslinking breaker aiming to remove unphysiological protein to protein binding is now under clinical trial (12). However, CML is not a crosslinking structure and is therefore less likely to be pathogenic. Distinguishing CML from non-CML AGE may be a prerequisite for understanding the role of AGE in the pathogenesis of diabetic complications and AGE-related disorders.

We prepared polyclonal antibodies by immunizing rabbits with AGE-rabbit albumin and then separated the antiserum into antibodies that recognized CML and non-CML AGE. Circulating AGE has the potential to be a marker of longterm glycemic control in diabetic patients (13) and recent studies have suggested that low-molecular-weight AGE peptides might be one of the uremic toxins in diabetic patients with end-stage renal disease $(14,15)$. On the basis these findings, we separately assessed the levels CML and nonCML AGE in type 2 diabetic patients and compared the results with hemoglobin $\mathrm{A}_{1 \mathrm{c}}\left(\mathrm{HbA}_{1 \mathrm{c}}\right)$ and fasting blood glucose levels. We also investigated the size distribution and clearance of serum CML and non-CML AGE in diabetic patients on hemodialysis. Separate evaluation of CML and non-CML AGE might be necessary for better understanding of the importance of circulating AGE and to facilitate efforts to develop therapy for diabetic complications based on AGE inhibitors.

\section{Materials and Methods}

\section{Materials}

Bovine ribonuclease (RNase), bovine serum albumin (BSA), human serum albumin (HSA), rabbit serum albumin (RSA), and human glycated serum albumin [glycated-HSA; 3 moles hexose (as fructosamine) per mole of albumin] were obtained from Sigma Chemical Co. (St. Louis, MO). D-glucose, glyoxylic acid, sodium borohydride $\left(\mathrm{NaBH}_{4}\right)$, and sodium cyanoborohydride $\left(\mathrm{NaCNBH}_{3}\right)$ were purchased from Wako Pure Chemical Industries (Osaka, Japan). A PD-10 column, an E-Z-SEP Polyclonal Kit, CNBr-activated Sepharose 4B, and Sephadex G-15 were purchased from Pharmacia Biotech (Uppsala, Sweden). Alkaline phosphatase (AP)-conjugated sheep anti-rabbit IgG antibody was purchased from Boehringer Mannheim (Mannheim, Germany). SuperBlock Blocking Buffer in phosphate-buffered saline (PBS) and alkaline phosphatase substrate kits were purchased from Pierce Chemical Co. (Rockford, IL). Microtitration plates (96-well; high binding E.I.A./R.I.A. plates) were purchased from Corning Costar (Cambridge, MA). Centriprep-10 and PM-10 ultrafiltration membranes were purchased from Amicon (Beverly, MA). All other chemicals were of the highest grade available from commercial sources.

\section{Preparation of AGE Proteins}

AGE-BSA, AGE-HSA, AGE-RSA, and AGERNase were prepared as previously described (16). Briefly, each protein was incubated under sterile conditions with $0.5 \mathrm{M}$ D-glucose and 1 mM EDTA in $0.2 \mathrm{M}$ phosphate buffer (pH 7.4) at $37^{\circ} \mathrm{C}$ for 8 weeks, and then low-molecularweight reactants and glucose were removed by dialysis against PBS (pH 7.4). AGE-BSA was reduced with $\mathrm{NaBH}_{4}$ as described previously (17).

\section{Preparation of CML Proteins}

CML-BSA and CML-RSA were prepared as described elsewhere $(4,18)$. Briefly, $50 \mathrm{mg} / \mathrm{ml}$ protein was incubated at $37^{\circ} \mathrm{C}$ for $24 \mathrm{hr}$ with $45 \mathrm{mM}$ glyoxylic acid and $150 \mathrm{mM} \mathrm{NaCNBH}$ in $2 \mathrm{ml}$ of $0.2 \mathrm{M}$ phosphate buffer ( $\mathrm{pH}$ 7.4), followed by extensive dialysis against PBS. 


\section{Preparation of Polyclonal Anti-AGE Antibodies}

Four milligrams of AGE-rabbit serum albumin (AGE-RSA) incubated for 4,8 , or 12 weeks was emulsified in $50 \%$ Freund's complete adjuvant and injected intradermally into rabbits. This procedure was repeated at weekly intervals for 6 weeks. After a 2-week pause, the rabbits were given a booster injection of $4 \mathrm{mg}$ of each antigen. Animals were bled on the tenth day after this injection and serum was obtained for further affinity purification.

Separation of CML and Non-CML AGE Antibodies from Polyclonal AGE Antibodies by Affinity Chromatography

Antibodies specific for CML or non-CML AGE were isolated from the antiserum by affinity chromatography. AGE-BSA or CML-BSA (100 $\mathrm{mg}$ ) was coupled to $20 \mathrm{ml}$ of $\mathrm{CNBr}$-activated Sepharose $4 \mathrm{~B}$ according to the method of Cuatrecasas (19). Total immunoglobulin was precipitated from $20 \mathrm{ml}$ of antiserum using E-ZSEP antibody purification reagent (Pharmacia Biotech) and the final precipitate was dissolved in $20 \mathrm{ml}$ of $50 \mathrm{mM}$ phosphate buffer ( $\mathrm{pH} \mathrm{9.0)}$. Twenty milliliters of this immunoglobulin solution was then applied to a column $(1.5 \times 5.5$ $\mathrm{cm}$ ) of Sepharose 4B coupled with AGE-BSA. After extensive washing with PBS, the adsorbed fractions were eluted with $0.2 \mathrm{M}$ glycine/ $\mathrm{HCl}$ buffer ( $\mathrm{pH} 2.5$ ). The AGE antibody fractions were pooled, neutralized with $1 \mathrm{M}$ Tris solution, concentrated using Centriprep-10 (Amicon), and passed through a PD-10 column (Pharmacia Biotech) equilibrated with PBS. The AGE antibodies then were loaded onto a CML-BSA-Sepharose 4B column $(1.5 \times 5.5 \mathrm{~cm})$, which was washed with $30 \mathrm{ml}$ of PBS to obtain the unadsorbed fraction (non-CML AGE antibody). The adsorbed fraction (CML antibody) was then eluted with $20 \mathrm{ml}$ of $0.2 \mathrm{M}$ glycine/ $\mathrm{HCl}$ buffer (pH 2.5), and the eluate was neutralized with 1 $M$ Tris solution. Fractions $(1.0 \mathrm{ml})$ were monitored for absorbance at $280 \mathrm{~nm}$. Both the adsorbed and unadsorbed fractions were pooled, concentrated with Centriprep-10, and passed through a PD-10 column equilibrated with PBS for use in our study. The immunoreactivity of each fraction to non-CML AGE- and CML-derivatives was determined by competitive ELISA, as described below.

\section{Enzyme-Linked Immunosorbent Assay (ELISA)}

Ligand inhibition and AGE measurements were performed with a competitive ELISA, as described elsewhere (16). Briefly, test samples (50 $\mu l)$ were added to each well as a competitor for $50 \mu \mathrm{l}$ of AGE antiserum (1:2000) or purified antibodies (1:250-1:1500), followed by incubation for $2 \mathrm{hr}$ at room temperature with gentle shaking on a horizontal rotary shaker. Results were expressed as $\mathrm{B} / \mathrm{B}_{0}$, calculated as (experimental OD - background OD)/(total OD background $\mathrm{OD}$ ). The immunoreactivity of each fraction was read from the calibration curve (AGE-BSA or CML-BSA) and was expressed as AGE or CML units (U)/ml, with 1 U corresponding to the amount of antibody reactive material found in AGE-BSA or CML-BSA at a protein concentration of $1 \mu \mathrm{g} / \mathrm{ml}$. The intra-assay and interassay $\mathrm{CV}$ of the ELISA were $6.2 \%$ and $12.4 \%$, respectively. The same set of experiments was repeated at least three times and representative data are shown in Figures 1-9.

\section{Determination of CML and Non-CML AGE in Type} 2 Diabetic Patients by Competitive ELISA

Circulating levels of CML and non-CML AGE were measured in type 2 diabetic patients using the competitive ELISA. The intra-assay and interassay CV of the ELISA were $6.2 \%(n=20)$ and $12.4 \%(n=12)$, respectively. Sixty-six serum samples from type 2 diabetic patients with no evidence of uremia and serum creatinine levels $<2 \mathrm{mg} / \mathrm{dl}$ were analyzed. The mean age was $52 \pm 11$ (mean $\pm \mathrm{SD}$ ), and the mean duration of diabete mellitus was $5.2 \pm 2.6$ years (mean \pm $\mathrm{SD})$. The correlation between non-CML AGE or $\mathrm{CML}$ and the level of $\mathrm{HbA}_{1 \mathrm{c}}$ the mean daily fasting blood glucose (FBG) level for the previous 1 month, or mean daily FBG level for the previous 2 months was assessed. $\mathrm{HbA}_{1 \mathrm{c}}$ levels were measured using an HPLC system (HLC-723 GHbIII, Tosoh, Tokyo, Japan). FBG levels were measured daily by the glucose oxidase method using Glucocard (Kyoto Dai-ichi Kagaku, Kyoto), a self-monitoring method.

\section{Size Distribution of Non-CML AGE and CML in} Serum from Diabetic Patients on Hemodialysis

Ten milliliters of serum from each diabetic patient on hemodialysis was concentrated by lyophilization and dissolved in $2 \mathrm{ml}$ of distilled water. This solution was applied to a Sephacryl S-200 column $(1.5 \times 110 \mathrm{~cm})$, which was 
equilibrated with PBS (pH 7.4) and eluted with the same buffer (fraction size: $1.5 \mathrm{ml}$, flow rate: $10 \mathrm{ml} / \mathrm{hr}$ ) in a cold room. The molecular weight markers used were aldolase (MW 160,000), BSA (MW 67,000), chymotrypsinogen $A$ (MW 25,000), and vitamin $B_{12}$ (MW 1355). Each fraction was monitored for absorbance at $280 \mathrm{~nm}$ and the AGE activity of each fraction was measured by the AGE-ELISA and by determining the characteristic AGE-specific fluorescence $(\mathrm{Ex}=360 \mathrm{~nm} / \mathrm{Em}=440 \mathrm{~nm})$. The immunoreactivity of each fraction was read from the calibration curve (AGE-BSA or CML-BSA) and was expressed as AGE or CML $\mathrm{U} / \mathrm{ml}$, as described above.

\section{Detection of Low-Molecular-Weight Fraction in Serum from Diabetic Patients on Hemodialysis}

Fifty milliliters of serum from each diabetic patient (obtained both before and after dialysis) was subjected to ultrafiltration (PM-10 membrane, cut-off $M W 10 \mathrm{kD}$, Amicon) to separate the high-molecular-weight (HMW $>10 \mathrm{kD}$ ) fractions from the low-molecular-weight (LMW $<10 \mathrm{kD}$ ) fractions. Then the LMW fractions were pooled, concentrated by lyophilization, and dissolved in a small volume of distilled water. The precipitate was removed by centrifugation at $10,000 \mathrm{rpm}$ for $10 \mathrm{~min}$ and the supernatant was applied to a Sephadex G-15 column $(1.5 \times 110 \mathrm{~cm})$, which was equilibrated with 50 $\mathrm{mM}$ ammonium acetate buffer $(\mathrm{pH} 7.4)$ and eluted with the same buffer (fraction size: $1.2 \mathrm{ml}$, flow rate: $8 \mathrm{ml} / \mathrm{hr}$ ) in a cold room. The molecular weight markers used were cytidine (MW 243), vitamin $B_{12}$ (MW 1355), and cytochrome c (MW 12,500). Each fraction was monitored for absorbency at $280 \mathrm{~nm}$ and the AGE activity of each fraction was measured by both AGE-ELISA and characteristic AGE-specific fluorescence (Ex = $360 \mathrm{~nm} / \mathrm{Em}=440 \mathrm{~nm}$ ). The immunoreactivity of each fraction was read from the calibration curve (AGE-BSA or CML-BSA) and was expressed as $A G E$ or $C M L ~ U / m l$, as described above.

\section{Statistical Analysis}

The paired and unpaired Student's $t$-test (twotailed) were used to compare mean values among the different groups and linear regression analysis was used to assess correlations. All data are shown as the mean \pm SEM, unless otherwise specified. A $p$ value of $<0.05$ was considered statistically significant.

\section{Results}

Characterization of the Immunogen

AGE formation by rabbit serum albumin (AGERSA) during incubation for 4,8 , and 12 weeks was monitored by AGE-specific fluorescence. Fluorescence was only associated with the AGE-RSA complex, and was not seen in the control mixtures of RSA with glucose (day 0 ) or without glucose (12 weeks of incubation). The excitation and emission maxima of AGE were 360 and $440 \mathrm{~nm}$, respectively, in close agreement with reported data (20). The peak fluorescence intensity was increased by 19-fold at 4 weeks of incubation, 28-fold at 8 weeks, and 39-fold at 12 weeks in comparison with that of nonglycated RSA (12 weeks of incubation without glucose). The electrophoretic profile on reducing SDS-PAGE revealed that control, nonglycated RSA migrated at $68 \mathrm{kD}$. On the other hand, AGE-RSA migrated much more slowly, yielding a broad band larger than $68 \mathrm{kD}$, and suggesting that covalently linked adducts of RSA had been formed nonenzymatically without any discernible degradation (data not shown).

\section{Characterization of AGE Antiserum}

We prepared anti-AGE immunoglobulin fractions from AGE antiserum from AGE-RSA (4, 8, and 12 weeks of incubation) immunized rabbits. These immunoglobulins were applied to an affinity column coupled with AGE-BSA to acquire purified AGE antiserum. Figure 1 shows the cross-reactivity for CML-BSA, AGE-BSA, and native BSA of the polyclonal antibodies obtained when AGE-RSA was incubated with glucose for 4 weeks, 8 weeks, or 12 weeks. Each antibody reacted with AGE-BSA, whereas no reaction was observed with native BSA (Fig. 1) or with BSA obtained by parallel incubation without glucose (data not shown). In crossreactivity studies, these antibodies only reacted weakly with CML-BSA when compared with AGE-BSA (Fig. 1). It therefore seemed likely that the polyclonal antiserum contained not only antibodies specific for CML adducts but also antibodies for non-CML AGE adducts.

Separation of CML and Non-CML AGE Antibodies from Polyclonal AGE Antibodies

The polyclonal AGE immunoglobulin fractions obtained after incubation of AGE-RSA (4, 8, or 12 weeks) were purified by AGE-BSA affinity chromatography and then were separated by CML-BSA affinity chromatography (Fig. 2). We calculated the proportion of antibodies bound to the CML affinity 

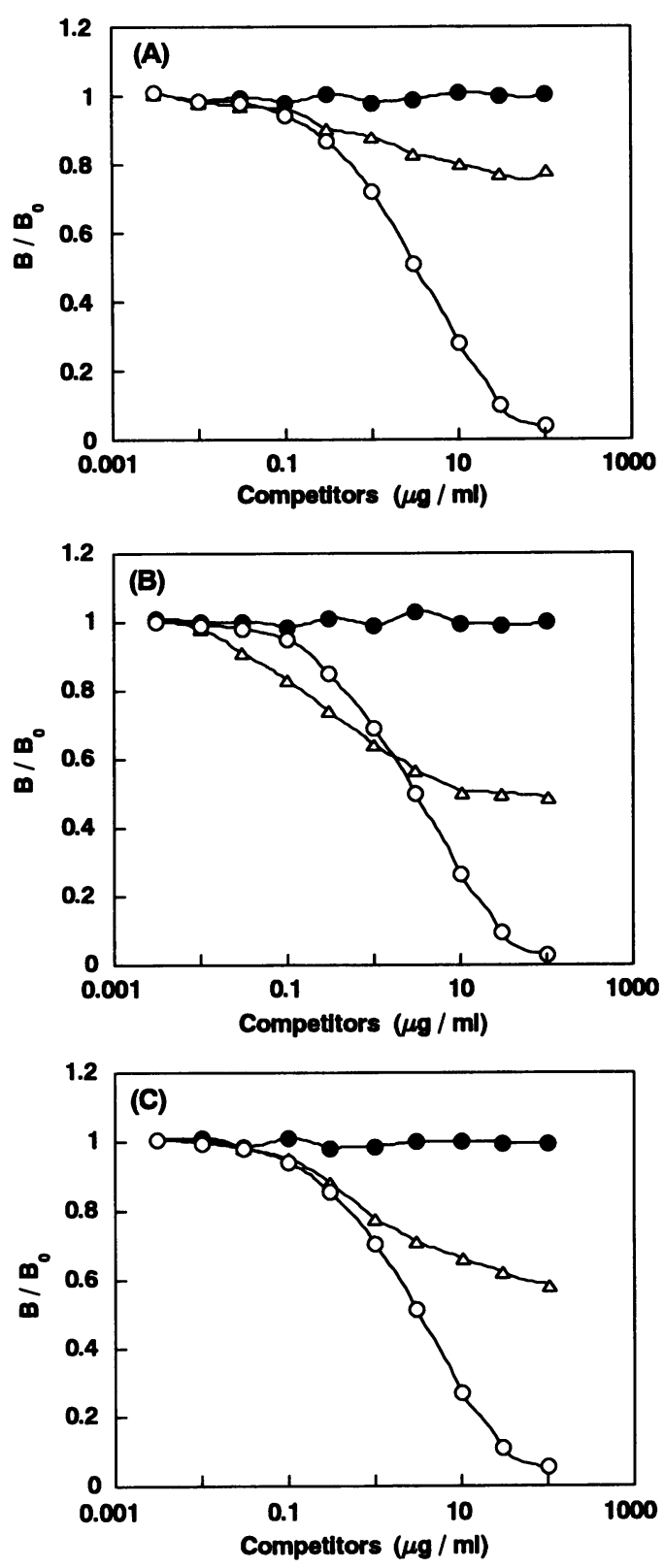

Fig. 1. Immunoreactivity of anti-AGE antiserum. The immunoreactivity of anti-AGE antiserum with AGE-BSA (O), CML-BSA $(\triangle)$, and native $B S A(O)$ was determined at various concentrations by competitive ELISA. Details are described in Materials and Methods. Antiserum prepared after incubation with glucose for 4 weeks (A), 8 weeks (B), and 12 weeks (C).

gel eluted as the second peak in Figure 2 and that of the antibodies unbound to CML affinity gel eluted as the first peak. Antibodies unbound to the CML affinity gel and eluted as the first peak (the non-CML AGE fraction) accounted for $60 \%$ of those obtained from 4-week AGE-RSA (Fig. 2A),
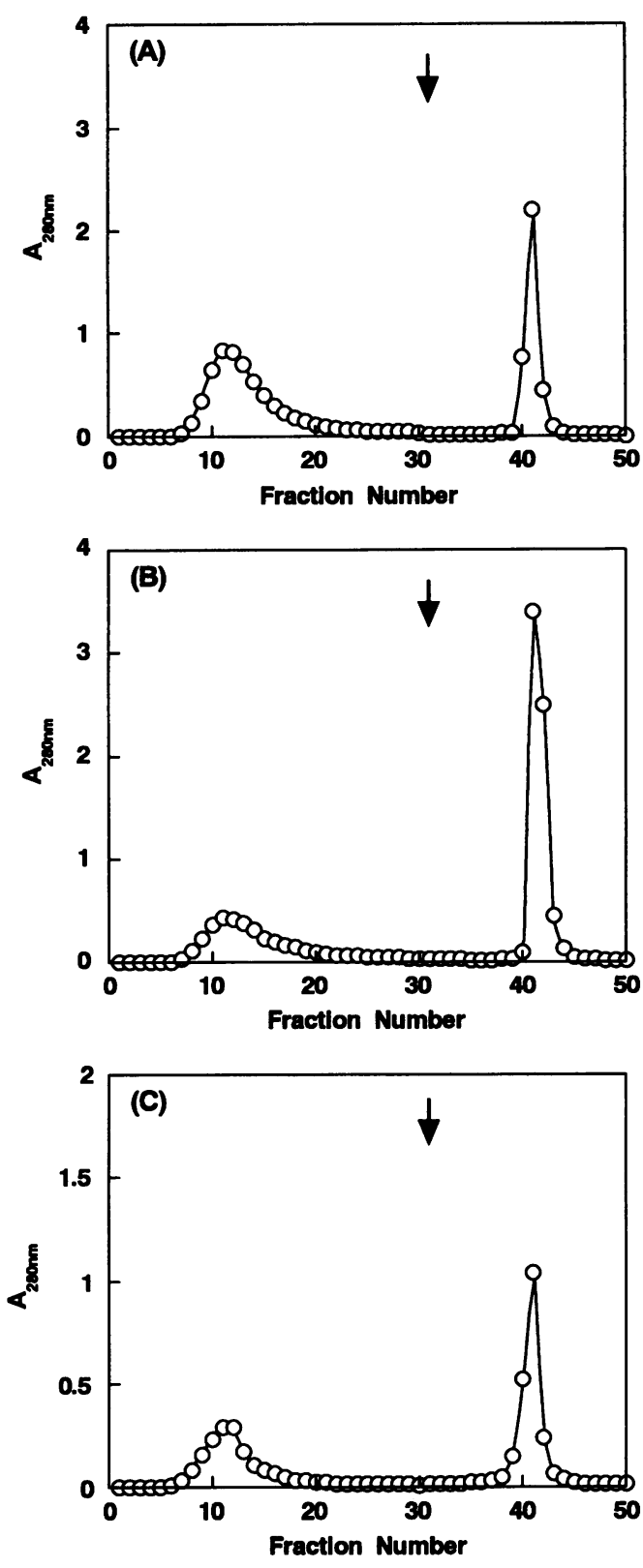

Fig. 2. Separation of CML and non-CML AGE antibodies from polyclonal AGE antibodies by CML-BSA affinity chromatography. Affinity chromatography was done with polyclonal antiAGE-RSA incubation for 4 weeks (A), 8 weeks (B), and 12 weeks $(\mathrm{C})$.

$35 \%$ of those obtained from 8-week AGE-RSA (Fig. 2B), and $50 \%$ of those obtained from 12week AGE-RSA (Fig. 2C).

\section{Characterization of Non-CML AGE Antibodies}

Characterization of the non-CML AGE antibodies obtained by CML-BSA affinity chromatogra- 

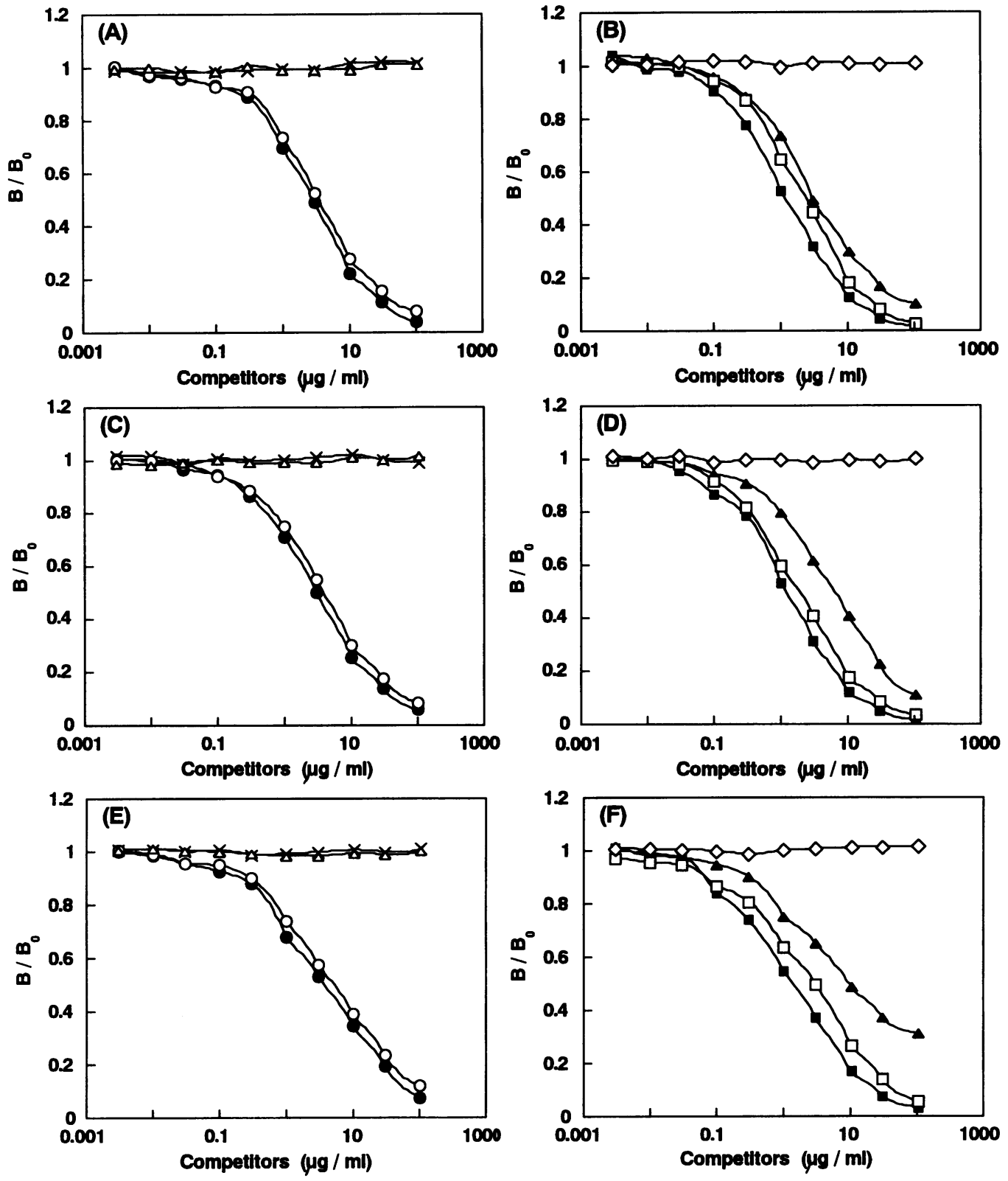

Fig. 3. Immunoreactivity of non-CML AGE antibodies with various AGE preparations. NonCML AGE antibody was obtained by 4-week (A, B), 8-week $(C, D)$, and 12-week (E, F) incubation of

AGE-RSA. (A, C, E) AGE-BSA (O), reduced AGEBSA $(O)$, glycated HSA $(\triangle)$, and BSA $(X)$. (B, D, F) AGE-HSA ( $(\mathbf{)})$, AGE-RSA ( $\square$ ), AGE-RNase ( $\square$ ), and CML-BSA $(\diamond)$.

phy was done using competitive ELISAs with several AGE-modified proteins, Amadori products, and CML-modified protein (Fig. 3). To determine whether Amadori products were recognized by these non-CML AGE antibodies, AGE protein was reduced with $\mathrm{NaBH}_{4}$. After reduction, the immunoreactivity of AGE-BSA remained essentially unchanged (Fig. 3A, C, E). Furthermore, non-CML AGE antibody binding to AGE-BSA was not altered by the addition of

glycated HSA, indicating that early glycation products such as Amadori products were not the antigenic epitopes. We also investigated whether non-CML AGE antibodies purified by CML-BSA affinity chromatography could react with CMLBSA. As shown in Figure 3B, D, F, CML-BSA did not inhibit non-CML AGE antibody binding to AGE-BSA. Pyrraline-BSA and pentosidine-BSA also did not inhibit the anti-AGE antibodies (data not shown), whereas AGE-HSA, AGE-RSA, and 

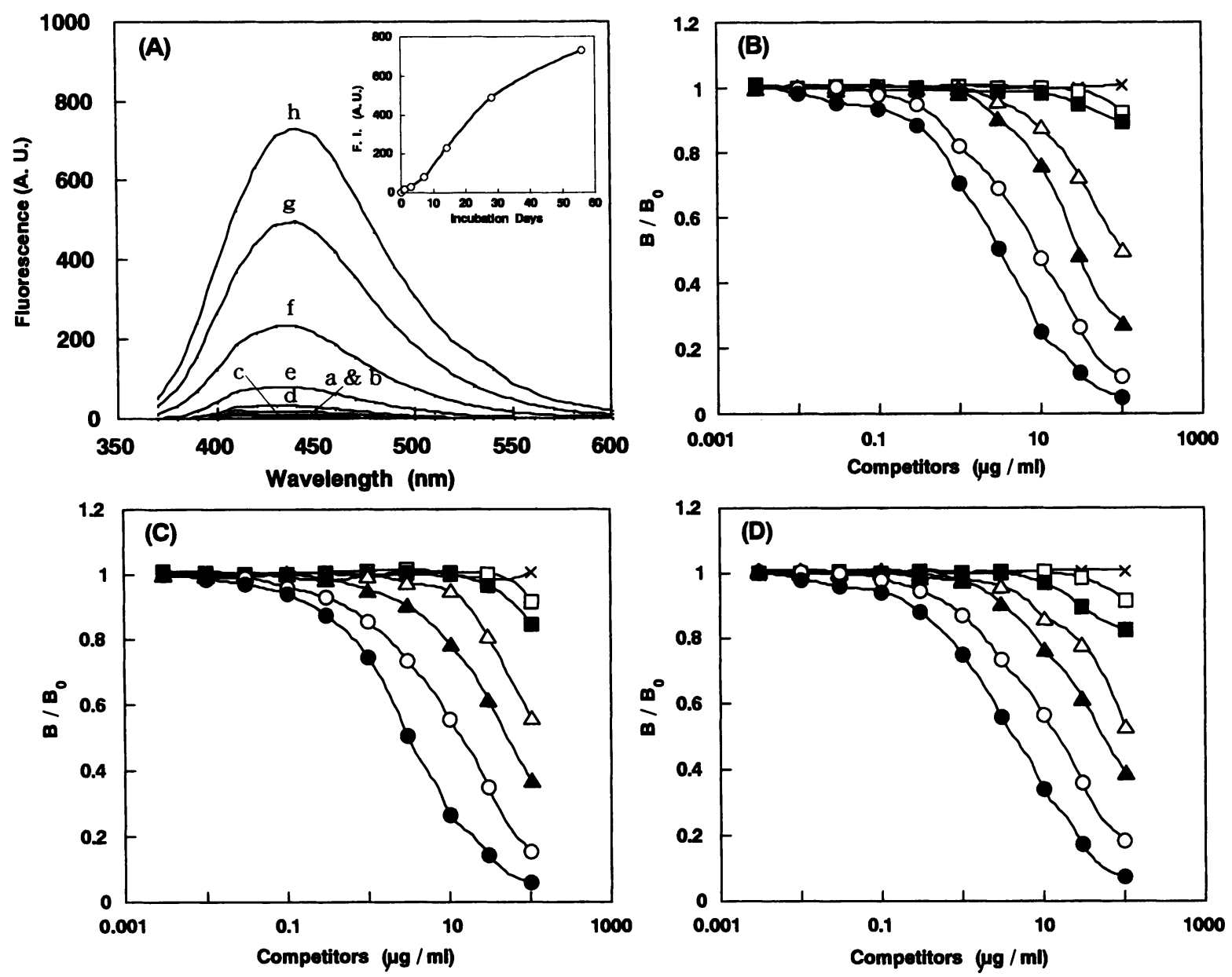

Fig. 4. Relation between AGE-associated fluorescence and immunoreactive AGE detected by each non-CML AGE antibody. (A) Fluorescence emission spectra of AGE-BSA (incubation times: a, 0 days; b, 8 weeks without glucose; $c, 1$ day with glucose; d, 3 days with glucose; e, 1 week with glucose; f, 2 weeks with glucose; $g$, 4 weeks with glucose; $h$, 8 weeks with glucose). Insert: Time course of the

AGE-RNase completely inhibited the binding. In addition, the reactivity of these non-CML AGE antibodies with AGE-BSA incubated with glucose for varying lengths of time was studied by competitive ELISA (Fig. 4). A time-dependent increase in fluorescence (Fig. 4A), concomitant with an increase in immunoreactivity, was observed when BSA was incubated with glucose (Fig. 4B-D). These results indicated that the nonCML AGE antibodies recognized AGE structures that were common to various AGE preparations and showed a time-dependent increase.

\section{Characterization of CML Antibodies}

Figure 5 shows the reactivity of each CML antibody with protein-bound CML and free CML.

development of AGE-specific fluorescence $(\mathrm{Ex}=$ $360, \mathrm{~nm} / \mathrm{Em}=440 \mathrm{~nm}$ ). (B-D) Immunoreactivity of AGE-BSA with non-CML AGE antibody obtained by 4-week (B), 8-week (C), and 12-week (D) incubation of AGE-RSA. Incubation times: 0 days $(X), 1$ day $(\square), 3$ days $(\square), 1$ week $(\triangle), 2$ weeks $(\Delta), 4$ weeks $(\bigcirc)$, and 8 weeks $(\Theta)$.

CML antibodies recognized a common epitope of the CML molecule and these antibodies did not react with the Amadori product (glycated HSA), unmodified protein (BSA), pentosidine-BSA, and pyrraline-BSA (data not shown). These results suggested that the CML antibodies specifically recognized CML. Free CML competed for the binding of CML antibodies to CML-BSA, whereas lysine had no effect. Sarcosin showed minor but significant competition, suggesting that the presence of an amino-carboxymethyl structure was essential for anti-CML recognition. The CML antibody obtained after 12 weeks incubation of AGE-RSA showed a much higher cross-reactivity with free CML and sarcosin (Fig. 5F) compared to the CML antibodies ob- 

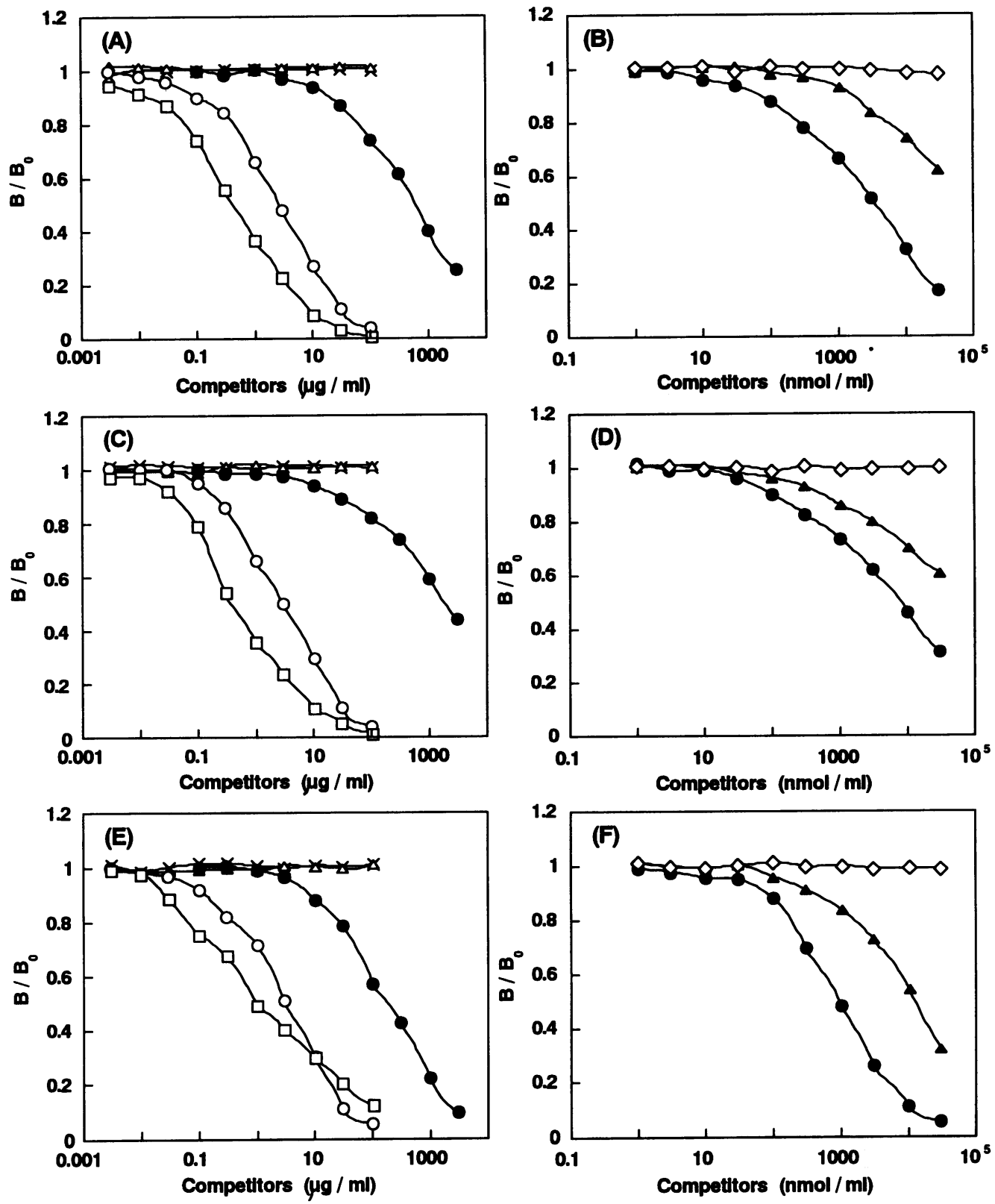

Fig. 5. Immunoreactivity of CML antibodies for CML protein and structurally related compounds. CML antibody was obtained by 4 -week (A, B), 8-week (C, D), and 12-week (E, F) incubation of AGE-RSA. The immunoreactivity of CML antibodies with BSA $(\times)$, glycated HSA $(\triangle)$, CML-BSA $(O)$,

tained after 4 or 8 weeks, incubation of AGERSA (Fig. 5B, D).

Determination of CML and Non-CML AGE in Type 2 Diabetic Patients by Competitive ELISA

Type 2 diabetic patients without uremia were studied using CML or non-CML AGE antibodies

CML-RSA ( $\square$ ), and free CML (O) was determined by competitive ELISA (A, C, E), as described in Materials and Methods. Immunoreactivity of CML antibodies with lysine $(\diamond), C M L(\Theta)$, and sarcosin $(\Delta)$ was also determined by competitive ELISA (B, D, F).

obtained by incubation of AGE-RSA with glucose for 12 or 8 weeks, respectively. In these patients, the serum non-CML AGE level was significantly correlated with the mean FBG level over the previous 1 month $(r=0.446, p=0.0002)$ or 2 months $(r=0.498, p<0.0001)$ (Fig. 6B or C). Serum non-CML AGE also showed a weak but significant correlation with $\mathrm{HbA}_{1 \mathrm{c}}(r=0.375$, 

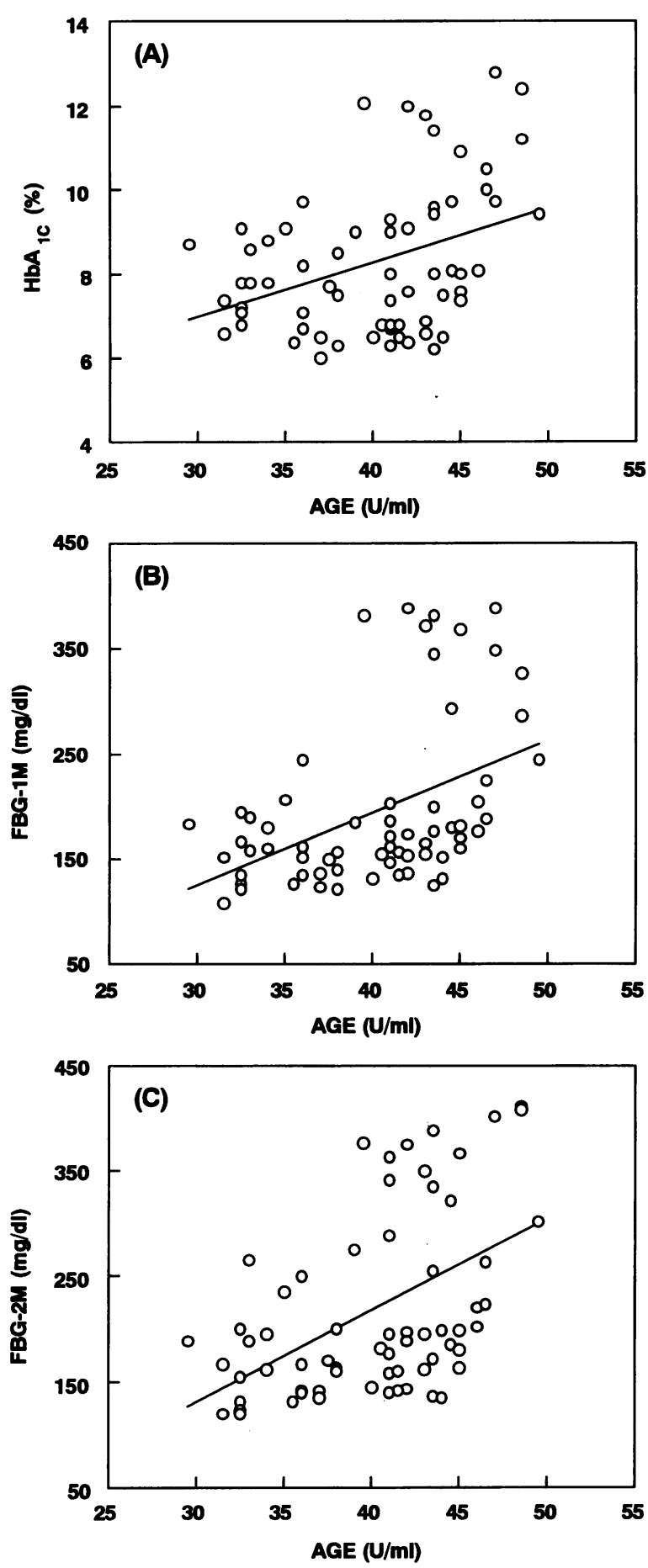

Fig. 6. Correlation between non-CML AGE level and $\mathrm{HbA}_{1 \mathrm{c}}$ (A) or the mean fasting blood glucose over the previous 1 month (FBG-1M) (B) or 2 months (FBG-2M) (C). The correlation coefficients were $r=0.375, p=0.0019$ (A); $r=0.446, p=$ 0.0002 (B); and $r=0.498, p<0.0001$ (C).

$p=0.0019$ ) (Fig. 6A). However, serum CML was not correlated with the mean FBG over the pre-
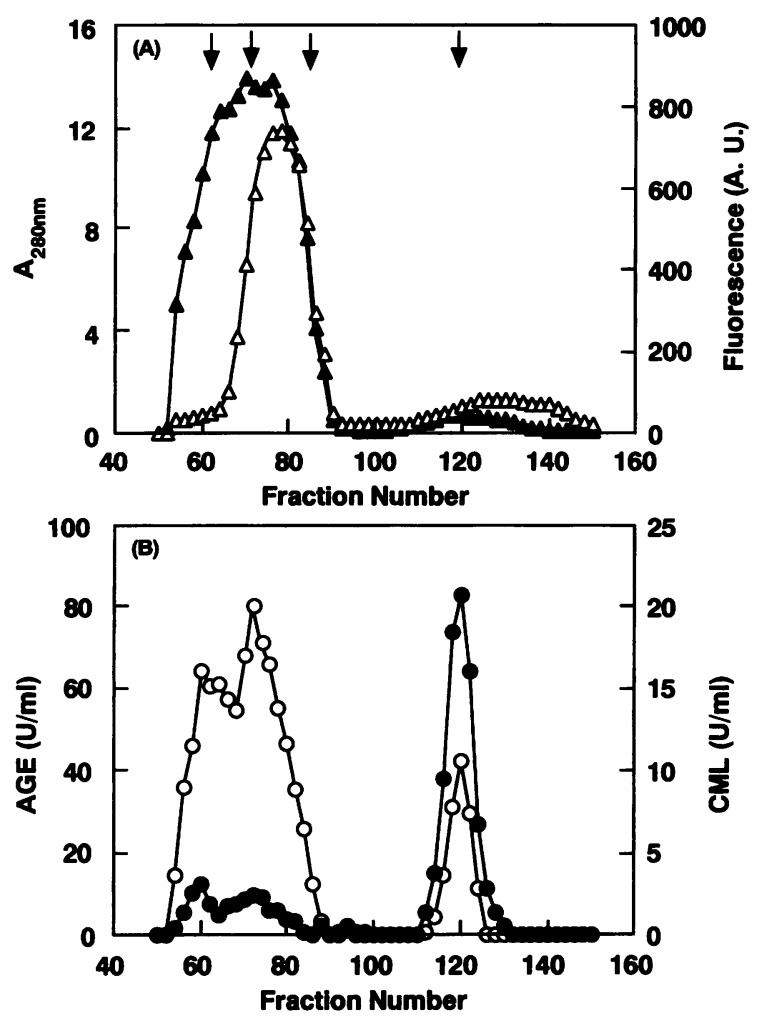

Fig. 7. Size distribution of AGE in serum from diabetic patients on hemodialysis. Serum from diabetic patients with end-stage renal disease on hemodialysis was subjected to gel filtration chromatography (Sephacryl S-200 column, $1.5 \times 110 \mathrm{~cm}$ ). Eluted fractions were monitored for non-CML AGE (O) and CML (O) by ELISA (data from triplicate determinations), AGE fluorescence $(\triangle: \mathrm{Ex}=360 \mathrm{~nm} /$ $\mathrm{Em}=440 \mathrm{~nm})$, and absorbance at $280 \mathrm{~nm}(\Delta)$. Elution of aldolase $(160,000 \mathrm{Da}), \mathrm{BSA}(67,000 \mathrm{Da})$, chymotrypsinogen $A(25,000 \mathrm{Da})$, and vitamin $\mathrm{B}_{12}$ (1355 Da) (molecular weight markers) is indicated by arrows. (A) Chromatography monitored by AGE fluorescence and absorbance at $280 \mathrm{~nm}$. (B) Chromatography with affinity-purified CML or non-CML AGE antibodies obtained using 12-week or 8-week AGE-RSA, respectively.

vious 1 month $(p=0.432)$ or 2 months $(p=$ $0.063)$ or with $\operatorname{HbA}_{1 \mathrm{c}}(p=0.254)$.

Size Distribution of AGE in Serum from Diabetic Patients on Hemodialysis

Using affinity-purified CML and non-CML AGE antibodies, we examined the size distribution of AGE in serum samples obtained from type 2 diabetic patients on hemodialysis. The size distribution of CML and non-CML AGE-containing molecules was determined by Sephacryl S-200 column chromatography. Figure 7A shows dis- 
tribution of the serum proteins/peptides monitored for absorbency at $280 \mathrm{~nm}$ and AGE-specific fluorescence. Figure $7 \mathrm{~B}$ shows the distribution detected by CML or non-CML AGE antibodies obtained after incubation of AGE-RSA with glucose for 12 or 8 weeks, respectively. Non-CML AGE immunoreactive material was eluted as three peaks, which contained species with apparent molecular weights of $200 \mathrm{kD}, 65 \mathrm{kD}$, and 1 $\mathrm{kD}$. CML immunoreactive material was also eluted as three peaks, which contained species of the same molecular weights. We further examined the AGE distribution of the low-molecularweight fractions ( $1 \mathrm{kD}$ fraction) in serum from the diabetic patients, using Sephadex G-15 column chromatography. Figure 8A shows the distribution of AGE in the low-molecular-weight fraction monitored for absorbency at $280 \mathrm{~nm}$ as well as for AGE-specific fluorescence. Figure 8B shows the distribution detected with the affinitypurified non-CML AGE and CML antibodies. Non-CML AGE immunoreactive material was eluted as two peaks, which contained species with an apparent molecular weight of $1.15 \mathrm{kD}$ and $0.85 \mathrm{kD}$ (Fig. 8B). CML immunoreactive material was also eluted as two peaks, which contained species of the same molecular weights.

\section{Clearance of AGE Protein/Peptide by Hemodialysis}

To compare the effects of hemodialysis on the clearance of AGE, we measured the serum levels of CML and non-CML AGE proteins/peptides in patients undergoing hemodialysis. When the highmolecular-weight fraction in serum was separated by gel filtration chromatography (Sephacryl S-200 column: $1.5 \times 110 \mathrm{~cm}$ ) before and after dialysis, it showed no changes with respect to the absorbance at $280 \mathrm{~nm}$, the AGE-specific fluorescence, and the CML and non-CML AGE proteins revealed by ELISA (data not shown). In contrast, hemodialysis induced a dramatic decrease in the absorbance at $280 \mathrm{~nm}$ and the AGE-specific fluorescence when the low-molecular-weight fractions were studied (Fig. 9A, B). However, the levels of non-CML AGE- and CML-peptides detected by the ELISA showed no difference before and after hemodialysis (Fig. 9C, D).

\section{Discussion}

In the present study, RSA modified by incubation with glucose was used to immunize rabbits and a high titer of antiserum without any reac-
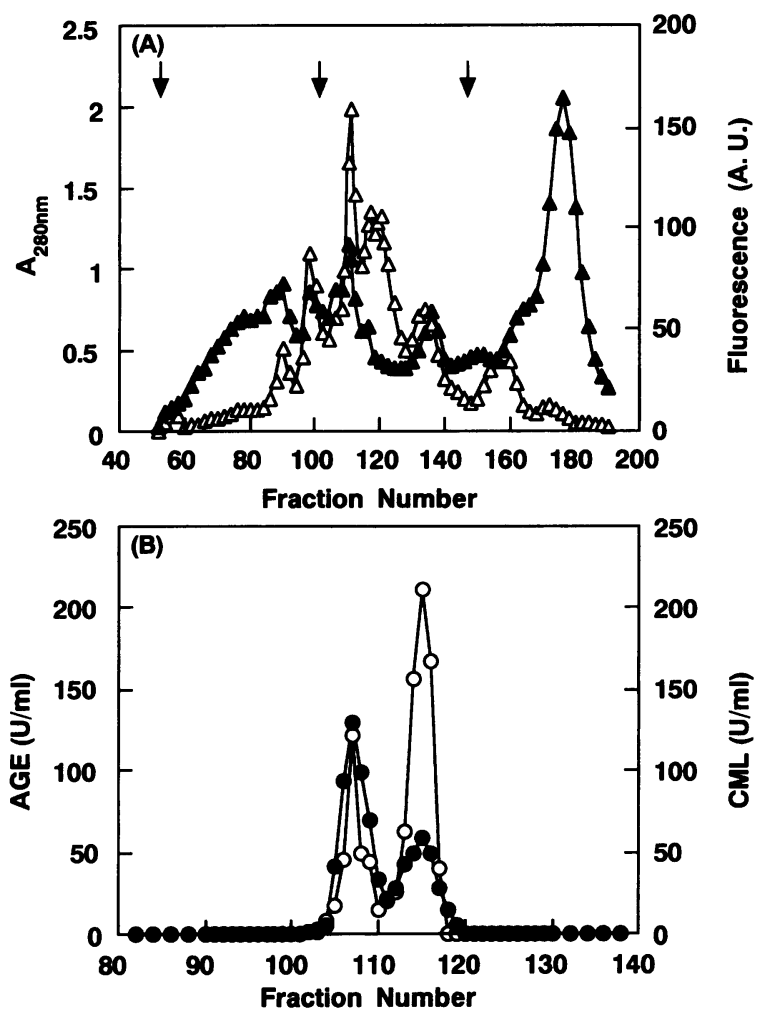

Fig. 8. Size distribution of the low-molecularweight AGE-peptide fraction from diabetic patients on hemodialysis. Low-molecular-weight serum fractions $(45 \mathrm{ml}$ ) obtained from diabetic patients with end-stage renal disease on hemodialysis were subjected to gel filtration chromatography (Sephadex G-15 column, $1.5 \times 110 \mathrm{~cm}$ ). Eluted fractions were monitored for non-CML AGE (O) and CML (O) by ELISA (data from triplicate determinations), AGE fluorescence $(\Delta)$, and absorbance at 280 $\mathrm{nm}(\triangle)$. Elution of cytochrome $\mathrm{c}\left(\mathrm{V}_{\mathrm{o}}\right)$, vitamin $\mathrm{B}_{12}$ (1355 Da), and cytidine (243 Da) (molecular weight markers) is indicated by arrows. (A) Chromatography monitored by AGE fluorescence and absorbency at $280 \mathrm{~nm}$. (B) Chromatography with affinity-purified CML or non-CML AGE antibodies obtained using 12-week or 8-week AGE-RSA, respectively.

tivity against the carrier protein was obtained. Using two affinity chromatography columns coupled with AGE-BSA or CML-BSA, we then separated antibodies directed against CML and non-CML AGE. We hypothesized that the nonCML AGE antibody may be more suitable for the detection of AGE moieties mainly derived from glycation in diabetic patients rather than from oxidation.

To prepare the AGE immunogen, we used three kinds of AGE-RSA obtained by incubation with glucose for different periods. We expected to find an incubation time-dependent increase in 

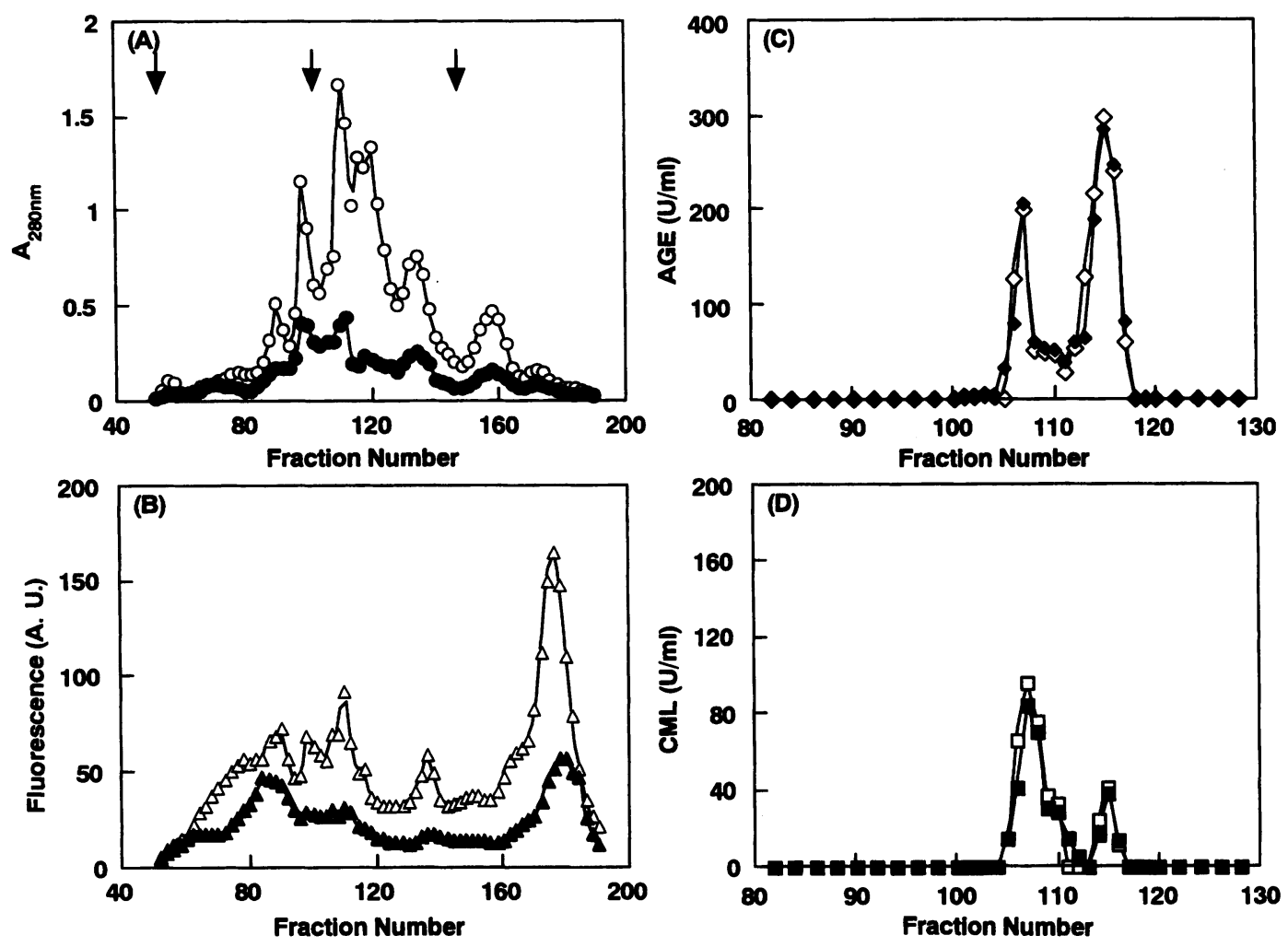

Fig. 9. Clearance of AGE peptide by hemodialysis. Pooled low-molecular-weight fractions $(<10,000)$ from serum samples of 10 subjects $(5 \mathrm{ml}$ from each subject) obtained before (open symbols) and after (closed symbols) hemodialysis were subjected to gel filtration chromatography using a Sephadex G-15 column $(1.5 \times 110 \mathrm{~cm})$. Eluted fractions were monitored for non-CML AGE $(\diamond$ or $\diamond)$ and CML ( $\square$ or $\square$ ) by ELISA (data from triplicate deter-

minations), AGE fluorescence ( $\triangle$ or $\Delta$ ), and absorbance at $280 \mathrm{~nm}(\mathrm{O}$ or $\bigcirc)$. Elution of cytochrome c $\left(V_{0}\right)$, vitamin $B_{12}(1355 \mathrm{Da})$, and cytidine (243 Da) (molecular weight makers) is indicated by arrows. Chromatography was monitored by absorbency at $280 \mathrm{~nm}(\mathrm{~A})$ and by AGE fluorescence (Ex $=360$ $\mathrm{nm} / \mathrm{Em}=440 \mathrm{~nm}$ ) (B). Chromatography with affinity-purified non-CML AGE antibody was obtained using 8-week (C) and 12-week (D) AGE-RSA.

the titer of CML and non-CML AGE antibodies. However, the specificity of the three antisera obtained after 4,8 , and 12 weeks of incubation showed little difference (Figs. 1-5). Among the CML antibodies, the antibody obtained after 12 weeks of incubation had a higher specificity compared to those obtained after 4 or 8 weeks (Fig. 5). In contrast, Figures 3 and 4 show that the specificity of non-CML AGE antibody was slightly higher after 8 weeks of incubation compared to that at 4 or 12 weeks. Thus, the duration of incubation used to produce AGE may influence antibody specificity.

Competition studies with anti-AGE antibodies detected cross-reactive AGE epitopes on a variety of carrier proteins, including RNase and albumins (Fig. 3). The non-CML AGE antibodies recognized epitopes that formed in a time-dependent fashion during the incubation of BSA with glucose (Fig. 4). These immunologically re-

active structures displayed fluorescence and were not reducible by $\mathrm{NaBH}_{4}$, suggesting the formation of common AGE structure(s) by incubation of the proteins with glucose. The epitope of non-CML AGE antibodies seemed to differ from pyrraline and pentosidine, which have been suggested as in vitro and in vivo candidates for AGE structures $(1,2,3)$, because BSA preparations conjugated with pyrraline and pentosidine were not recognized by these antibodies (data not shown).

Although the CML antibodies yielded similar competition curves for CML proteins and free CML, protein-bound CML competed much more effectively than free CML, thereby indicating a high affinity of the antibodies for protein-bound CML (Fig. 5). The CML antibodies competed for binding not only with CML but also with structurally related compounds (Fig. 5). These results correspond to reports that a monoclonal AGE 
antibody recognized the CML epitope $(7,9)$. Taken together, these data indicate that the nonCML AGE antibodies specifically recognized common AGE structure(s) in proteins and CML antibodies specifically recognized the CML modification of proteins.

Reddy et al. (8) assessed the specificity of anti-AGE antiserum obtained by immunization with AGE-KLH and found that CML-BSA completely inhibited antigen-antibody formation, indicating that $\mathrm{CML}$ is a major epitope for AGE antiserum. In contrast, a polyclonal AGE antibody prepared with AGE-RNase did not recognize free $C M L$, although the reactivity for protein-bound CML was not assessed (16).

We next examined whether the CML and non-CML AGE antibodies could detect AGE formed in vivo by applying these antibodies to an ELISA system. In the clinical measurement of AGE, the most convenient sample to test is blood, so we used an ELISA to measure CML and non-CML AGE in serum (Fig. 6). Serum nonCML AGE levels were significantly correlated with the mean FBG over the previous 1 or 2 months and with $\mathrm{HbA}_{1 \mathrm{c}}$ in type 2 diabetic patients, but CML levels were not correlated with these clinical parameters. These findings suggested that non-CML AGE, but not CML, might serve as a marker of long-term glycemic control in type 2 diabetes. Recent reports have demonstrated the existance of CML in serum and tissure samples $(7,21)$. Fu et al. reported that the main source of CML was lipid peroxidation, and they suggested that CML might be a marker of oxidative stress and not glycation or AGE (10). Subsequently, Wells-Knecht et al. demonstrated that there was no evidence of increased oxidative stress in diabetes, although the method of evaluating CML was different from ours (11). Therefore, non-CML AGE may mainly represent the extent of glycation, whereas CML may mainly represent the extent of oxidation in diabetes mellitus.

Both high-molecular-weight AGE, which might represent protein-bound AGE, and lowmolecular-weight AGE, which might represent peptide-bound AGE, have been detected in the blood of diabetic patients with renal failure $(14,15)$. The estimated weight of low-molecular AGE peptide(s) detected by previous AGE-ELISA systems was between 1 and $2 \mathrm{kD}(14,15,22)$. In the present study, CML and non-CML AGE immunoreactive material eluted as two peaks with apparent molecular weights of 1.15 and $0.85 \mathrm{kD}$ (Fig. 8). This provided the first evidence for the coexistence of both CML and non-CML AGE within AGE-peptides in the blood.

In summary, we prepared specific antibodies recognizing CML and non-CML AGE structures in vivo. These antibodies revealed the coexistence of both CML and non-CML AGE in circulating AGE peptides. Clinical parameters of glycemic control were significantly correlated with non-CML AGE levels, but not with CML levels. New treatments aimed at inhibiting AGE may be important to prevent the complications of diabetes as well as preventing disorders related to aging (23). Our findings shed some light on the complex mechanism of AGE formation and the relation between CML and non-CML AGE. In addition, the use of ELISA for separate evaluation of CML and non-CML AGE in vivo may be of some value in studies on treatment to ameliorate the complications of diabetes.

\section{Acknowledgments}

We are grateful to Dr. Toshio Miyata (Tokai University School of Medicine) for providing pentosidine-BSA and free CML, to Dr. Satoshi Miyata (Kobe University School of Medicine) for providing pyrraline-BSA, and to Dr. Takashi Fusegawa (Sapporo Shakaihoken General Hospital) for providing serum from the diabetic patients on hemodialysis. These studies were supported in part by a Grant-in-Aid for Scientific Research (\#09470204) to Z.M. from the Japanese Ministry of Education, Science, Sports, and Culture, and by a Health Science Research Grants (\#H10Chozyu-033) to Z.M. from the Japanese Ministry of Health and Welfare, Japan.

\section{References}

1. Brownlee MA, Cerami A, Vlassara H. (1988) Advanced glycosylation endproducts in tissue and the biochemical basis of diabetic complications. N. Engl. J. Med. 318: 1315-1321.

2. Hayase F, Nagaraj RH, Miyata S, Njoroge FG, Monnier VM. (1989) Aging of proteins: immunological detection of a glucose-derived pyrrole during Maillard reaction in vivo. J. Biol. Chem. 263: 3758-3764.

3. Sell DR, Monnier VM. (1989) Structure elucidation of a senescence cross-link from human extracellular matrix. J. Biol. Chem. 264: 21597-21602.

4. Ahmed MU, Thorpe SR, Baynes JW. (1986) Identification of $\mathrm{N}^{\epsilon}$-(carboxymethyl)lysine as a degradation product of fructose lysine in glycated protein. J. Biol. Chem. 261: 4889-4894. 
5. Nakamura $\mathrm{K}$, Hasegawa T, Fukunaga $\mathrm{Y}$, Ienaga $\mathrm{K}$. (1992) Crosslines A and B as candidates for the fluorophores in age- and diabetes-related crosslinked proteins, and their diacetates produced by Maillard reaction of $\alpha-N$-acetyl-L-lysine with Dglucose. J. Chem. Soc. Chem. Commun. 14: 992-994.

6. Niwa T, Katsuzaki T, Miyazaki S, et al. (1997) Immunohistochemical detection of imidazolone, a novel advanced glycation end product, in kidneys and aortas of diabetic patients. J. Clin. Invest. 99: 1272-1280.

7. Schleicher ED, Wagner E, Nerlich AG. (1997) Increased accumulation of the glycoxidation product $\mathrm{N}^{\epsilon}$-(carboxymethyl)lysine in human tissues in diabetes and aging. J. Clin. Invest. 99: 457-468.

8. Reddy S, Bichker J, Welks-Knecht KJ, Thorpe SR, Baynes JW. (1995) $\mathrm{N}^{\epsilon}$-(carboxymethyl)lysine is a dominant advanced glycation end product (AGE) antigen in tissue proteins. Biochemistry 34: 1087210878.

9. Ikeda $K$, Higashi $T$, Sano $H$, et al. (1996) $\mathrm{N}^{\epsilon}$ (carboxymethyl)lysine protein adduct is a major immunological epitope in proteins modified with advanced glycation end products of the Maillard reaction. Biochemistry 35: 8075-8083.

10. Fu MX, Requena JR, Jenkins AJ, Lyons TJ, Baynes JW, Thorpe SR. (1996) The advanced glycation end product, $\mathbf{N}^{\epsilon}$-(carboxymethyl)lysine, is a product of both lipid peroxidation and glycoxidation reactions. J. Biol. Chem. 271: 9982-9986.

11. Wells-Knecht MC, Lyons TJ, McCance DR, Thorpe SR, Baynes JW. (1997) Age-dependent increase in ortho-tyrosine and methionine sulfoxide in human skin collagen is not accelerated in diabetes. J. Clin. Invest. 100: 839-846.

12. Vasan S, Zhang X, Zang Z, et al. (1996) An agent cleaving glucose-derived protein cross-links in vitro and in vivo. Nature 382: 275-278.

13. Wolffenbuttel BHR, Giordano D, Founds HW, Bucala R. (1996) Long-term assessment of glucose control by haemoglobin-AGE measurement. Lancet 347: 513-515.
14. Makita Z, Bucala R, Rayfield EJ, et al. (1994) Reactive glycosylation endproducts in diabetic uremia and treatment of renal failure. Lancet 343: 1519-1522.

15. Papanastasiou P, Grass L, Rodela H, Patrikarea A, Oreopoulos D, Diamandis FP. (1994) Immunological quantification of advanced glycosylation endproducts in the serum of patients on hemodialysis or CAPD. Kidney Int. 46: 216-222.

16. Makita Z, Vlassara H, Cerami A, Bucala R. (1992) Immunochemical detection of advanced glycosylation end products in vivo. J. Biol. Chem. 267: 5133-5138.

17. Nakayama H, Taneda S, Kuwajima S, et al. (1989) Production and characterization of antibodies to advanced glycation products on proteins. Biochem. Biophys. Res. Commun. 162: 740-745.

18. Dunn JA, Mccance DR, Thorpe SR, Lyons TJ, Baynes JW. (1991) Age-dependent accumulation of $\mathrm{N}^{\epsilon}$-(carboxymethyl)lysine and $\mathrm{N}^{\epsilon}$-(carboxymethyl)hydroxylysine in human skin collagen. Biochemistry 30: 1205-1210.

19. Cuatrecasas P. (1970) Protein purification by affinity chromatography. J. Biol. Chem. 245: 30593065.

20. Monnier VM, Kohn RR, Cerami A. (1984) Accelerated age-related browning of human collagen in diabetes mellitus. Proc. Natl. Acad. Sci. U.S.A. 82: 583-587.

21. Berg T, Clausen JT, Torjesen AP, Dahl-Jorgensen K, Bangstad HJ, Hanssen KF. (1998) The advanced glycation end product $\mathrm{N}^{\epsilon}$-(carboxymethyl)lysine is increased in serum from children and adolescents with type 1 diabetes. Diabetes Care 21: 1997-2002.

22. Makita Z, Radoff S, Rayfield EJ, et al. (1991) Advanced glycosylation end products in patients with diabetic nephropathy. N. Engl. J. Med. 325: 836-842.

23. Makita Z, Vlassara H, Rayfield E, et al. (1992) Hemoglobin-AGE: a circulating marker of advanced glycosylation. Science 258: 851-853. 